\title{
Interruption of recently induced immune responses by oral administration of antigen
}

\section{A.A. Conde, \\ B. Stransky, \\ A.M.C. Faria \\ and N.M. Vaz}

Departamento de Bioquímica e Imunologia, Instituto de Ciências Biológicas, Universidade Federal de Minas Gerais, Belo Horizonte, MG, Brasil

\section{Correspondence \\ N.M. Vaz \\ Laboratório de Imunobiologia \\ Departamento de Bioquímica e \\ Imunologia, ICB, UFMG \\ Caixa Postal 486 \\ 31161-970 Belo Horizonte, MG \\ Brasil \\ Fax: 55 (031) 441-5963 \\ Research supported by CNPq (No. 530349/93) and FAPEMIG (No. 1248/95).}

Received April 15, 1997

Accepted October 13, 1997

\begin{abstract}
Interest in oral tolerance has been renewed in the last few years as a possibility of intervention in human autoimmune diseases. An obstacle in this direction is that, although easily induced in animals virgin of contact with the antigen, oral tolerance becomes hard to induce in previously immunized animals. The present results show that there is an early period after primary immunization in which prolonged oral exposure to the antigen may arrest ongoing immune responses. Beyond this period, oral exposures to the antigen become ineffective and may actually boost immune responses. The end of the susceptible period coincides with the emergence of free specific antibodies in serum. However, the previous administration of purified anti-ovalbumin antibodies $(40 \mu \mathrm{g})$ was unable to block the induction of oral tolerance to ovalbumin in normal mice.
\end{abstract}

The intestinal mucosa is the largest surface exposed by the organism to its environment and is in contact with a plethora of antigenic materials. Small amounts of incompletely degraded or intact proteins regularly penetrate the circulation and antibodies to dietary antigens are a common finding in normal individuals $(1,2)$. However, another and possibly more frequent consequence of feeding is the development of oral tolerance - an apparent inhibition of specific immune responses to previously ingested proteins $(3,4)$.

Easily induced in animals virgin of previous exposure to the antigen, oral tolerance becomes difficult to induce in primed or immune animals $(5,6)$. Nevertheless, the development of ways of blocking ongoing im- mune responses by oral tolerance would be particularly important in the therapy of many forms of allergy (7) and autoimmune diseases $(8,9)$.

In the present study, we show that, early in their induction, ongoing immune responses in the mouse may be interrupted by intensive and prolonged ingestion of, or gavage with solutions containing the antigen. After a period of two weeks, concomitantly with the emergence of specific antibodies in serum, immune responsiveness is no longer reversed by oral contacts with the antigen.

We used 6- to 8-week-old B6D2F1 (C57BL/6 x DBA/2J) F1 mice of both sexes. Crystallized hen ovalbumin (Ova) was used as antigen. Ova V (grade V; Sigma Chemical Co., St. Louis, MO) was used for immuniza- 
Figure 1 - Secondary anti-Ova immune responses (ELISA ${ }^{*}$ ) in B6D2F1 mice gavaged with 20 $\mathrm{mg}$ Ova at different days before, during or after parenteral $(s c)$ immunization. Controls were gavaged with either $20 \mathrm{mg}$ Ova (tolerant control) or $0.5 \mathrm{ml}$ saline (immune control) on day -7 and received tap water thereafter. Parenteral (sc) immunizations: primary (day 0) $10 \mu \mathrm{g}$ Ova +1 mg Al(OH) 3 ; secondary (day 14) $10 \mu \mathrm{g}$ soluble Ova. Bleeding: day 21. Data are reported as means \pm SEM for $N=4-6$. ${ }^{*} \mathrm{P}<0.05$ compared to saline controls (Scheffé (ANOVA) test).

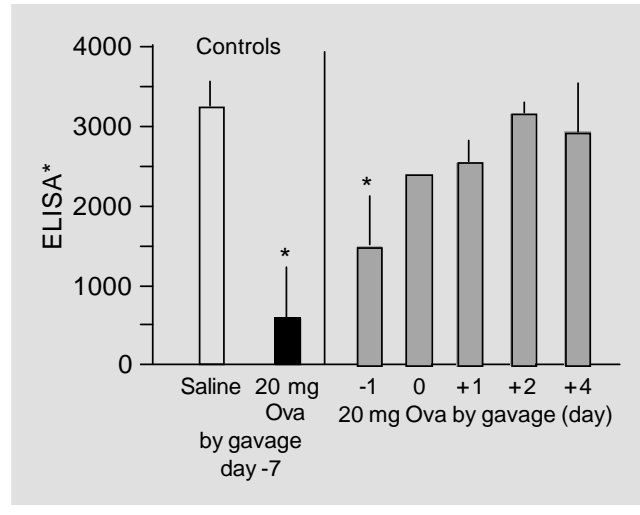

tions and ELISA and Ova III (grade III, Sigma) for oral tolerance induction. In oral tolerance induction, mice were lightly anesthetized with ether and received a single dose of $20 \mathrm{mg}$ Ova III in $0.5 \mathrm{ml}$ saline $(0.15$ $\mathrm{M} \mathrm{NaCl}$ ) by gavage 7 days before primary immunization; control mice were gavaged with $0.5 \mathrm{ml}$ saline. Alternatively, oral tolerance was induced by drinking a $1 / 5$ dilution of whole egg white in water daily for 3 or 7 consecutive days, as the exclusive liquid source; individual mice consumed approximately $20 \mathrm{mg}$ Ova within $24 \mathrm{~h}$; control mice drank tap water. After oral exposure to Ova, mice were immunized subcutaneously $(s c)$ or intraperitoneally (ip) with $10 \mu \mathrm{g}$ Ova +1 $\mathrm{mg} \mathrm{Al}(\mathrm{OH})_{3}$ in $0.2 \mathrm{ml}$ saline; after 14 or 21 days, they were boosted ( $s c$ or ip) with $10 \mu \mathrm{g}$ soluble Ova in $0.2 \mathrm{ml}$ saline and retroorbital bleedings for antibody assays were performed 7 days after the booster. Treatments aiming at the interruption of ongoing immune responses (gavages with $20 \mathrm{mg}$ Ova or drinking egg white dilutions for 3 or 7 consecutive days) were installed either immediately after primary immunization or 1 to 21 days thereafter, as indicated in the text.

Anti-Ova antibodies were titrated by ELISA as previously described (10). The results (designated ELISA*) are reported as the mean \pm SEM of the sums of absorbance values read between $1 / 100$ and $1 / 12,800$ serum dilutions. In our model, readings of positive (immune) sera fell in the most linear part of the absorbance curve. Extensive test- ing in our laboratory and consulting with statisticians confirmed that the results expressed by ELISA*, which are based on readings of 6 dilutions of each individual serum, are more reliable than evaluations based on a single serum dilution ("antibody titer" or those referred to as a standard antibody curve). Moreover, essentially the same results were obtained by evaluation based on a single serum dilution ("antibody titer"). Statistical significance $(\mathrm{P}<0.05)$ of differences between means was assessed by the Scheffé (ANOVA) test.

Specific anti-Ova antibodies were purified by affinity chromatography of pooled B6D2F1 anti-Ova sera collected after ip immunization with $100 \mu \mathrm{g}$ Ova in complete Freund's adjuvant (Difco, Detroit, MI), by passage through an Ova-Sephadex column with a peristaltic pump overnight at $4^{\circ} \mathrm{C}$. Immunoglobulins not bound to the column were washed with PBS (0.15 M, pH 7.5). Anti-Ova antibody was eluted with glycine$\mathrm{HCl}$ buffer, $\mathrm{pH} 2.8$, and the $\mathrm{pH}$ of the eluate was buffered with Tris- $\mathrm{HCl}, \mathrm{pH}$ 8.5. The protein concentration of the solutions was determined by absorbance at $280 \mathrm{~nm}$.

As shown in Figure 1, a single gavage with $20 \mathrm{mg}$ Ova performed either 7 days or 1 day $(24 \mathrm{~h})$ before immunization $(s c)$ with Ova plus $\mathrm{Al}(\mathrm{OH})_{3}$ resulted in marked oral tolerance. The same gavage carried out concomitantly or subsequently to $s c$ primary immunization failed to significantly alter the magnitude of secondary antibody responses. Gavage either with a curved needle in unanesthetized mice or by gastric intubation in anesthetized mice and the ingestion of egg white dilutions were similarly efficient for tolerance induction (data not shown).

As opposed to a single gavage, multiple (3 to 10) consecutive daily exposures blocked ongoing antibody responses, provided they were started soon after primary immunization. The ingestion of egg white for 7 days starting 0 or 3 days after primary immunization inhibited secondary anti-Ova responses 
(Figure 2), whereas ingestion starting at day 10 was on the fringe of effectiveness. The result of ingestion of egg white for only 3 consecutive days, starting on the same days, was less impressive. Ingestion of egg white for 7 days starting 14 days after primary immunization had no effect on the magnitude of secondary antibody responses. Gavages with $20 \mathrm{mg}$ Ova for 7 consecutive days starting 21 days after primary immunization was also ineffective (data not shown).

The passive transfer of specific antibodies has been previously shown to interfere with the induction of oral tolerance $(5,6)$; transfer of low doses $(10 \mu \mathrm{g})$ of antibodies was effective, probably because only trace amounts of antigenically intact ovalbumin are absorbed $(1,2)$. In the present experiments, however, the transfer of $40 \mu \mathrm{g}$ of affinity-purified mouse polyclonal anti-Ova antibodies $24 \mathrm{~h}$ before, concomitantly or 24 $\mathrm{h}$ after gavage with Ova failed to block the development of oral tolerance. This passive transfer of antibodies also had little or no effect on the magnitude of antibody responses of control mice gavaged with saline.

Whether oral contacts with antigens will result in oral tolerance, "local" or "systemic" immunization, i.e., circulating antibody formation, depends on several factors, related to the antigen and/or the organism $(5,6,10$, 11). Oral tolerance may occur concomitantly with local SIgA production (12); or, both systemic and local inhibition of sIgA production may occur (13); or, the intestinal IgA response may be blocked even more effectively than systemic responses (14). Which type of immunological consequences will result from oral exposures to antigen is as yet unresolved. Previous parenteral exposures to antigen interfere with subsequent mucosal IgA responses to the antigen (15), a phenomenon which is the mirror image of oral tolerance, and concomitant oral/parenteral exposures to antigen may block oral tolerance (Lahmann WM and Vaz N, unpublished observations).

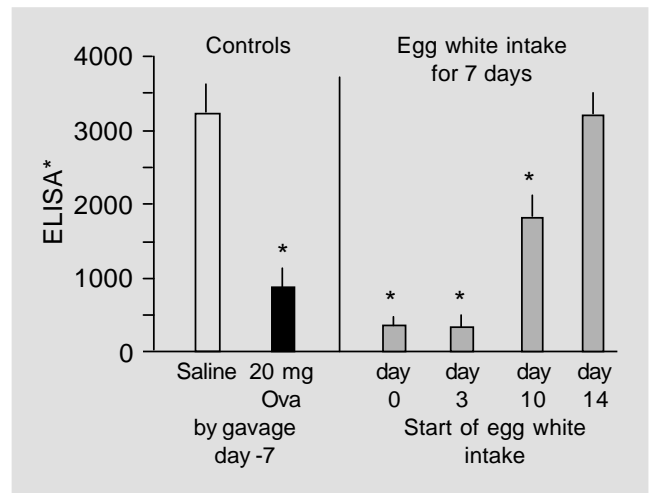

Oral exposure of previously immunized animals to antigen fails to induce tolerance (10-12) and may result in secondary serum and/or mucosal antibody responses $(5,6)$, although prolonged exposures have been shown to block the formation of IgE antibodies (16) or delayed type hypersensitivity (17). Regardless of these pending issues, several empirical attempts have been and are presently being made to treat human autoimmune diseases by intensive and prolonged feeding of proteins considered to be relevant immunogens in triggering these diseases (9).

Specific antibodies become detectable in serum (as determined by ELISA or radioimmune assays) at 9 to 10 days after primary immunization of $\mathrm{B} 6 \mathrm{D} 2 \mathrm{~F} 1$ mice with small (microgram) doses of Ova in $\mathrm{Al}(\mathrm{OH})_{3}$ $(5,10,11)$. The avoidance of voluntary ingestion of Ova-containing solutions by Ovaimmunized mice, the most sensitive clue of active immunization with low doses of protein, emerges between 10 and 14 days after primary immunization, concomitantly with the rise of detectable antibody titers in serum (18).

Intestinal dendritic cells containing orally administered antigens and able to stimulate $\mathrm{T}$ cells may be found in the lymph of the thoracic duct a few hours after antigen ingestion (19) and the presentation of peptides may have been irreversibly determined at this point.

In conclusion, the present results show that intensive and prolonged exposure to the antigen by direct feeding is only effective in
Figure 2 - Secondary anti-Ova immune responses (ELISA ${ }^{*}$ ) in B6D2F1 mice drinking diluted (1/ 5) egg white for 7 consecutive days starting 0,3 or 10 days after primary immunization. Controls were gavaged with $20 \mathrm{mg}$ Ova (tolerant) or $0.5 \mathrm{ml}$ saline (immune) on day -7 and received tap water thereafter. Parenteral (sc) immunizations as in Figure 1. Data are reported as means \pm $\mathrm{SEM}$ for $\mathrm{N}=4-6$. ${ }^{*} \mathrm{P}<0.05 \mathrm{com}$ pared to saline controls (Scheffé (ANOVA) test). 
blocking the effects of parenteral immunization when initiated shortly after primary immunization. Recently developed techniques of antigen delivery in the gastrointestinal tract by coupling with cholera toxin B subunit or micro-encapsulation (20) are potentially able to modify this situation.

\section{Acknowledgments}

We thank Ms. Ilma Marsal de Souza for competent care of the animal colonies and Ms. Frankcinéia Aparecida de Assis and Ms. Ilma Marsal de Souza for technical assistance.

\section{References}

1. Hemmings WA (1978). Antigen Absorption by the Gut. MTP Press, Lancaster, England.

2. Neutra MR \& Kraehenbuhl J-P (1992). Transepithelial transport and mucosal defence. I. The role of $\mathrm{M}$ cells. Tips in Cell Biology, 2: 134-138.

3. Mowat AM (1994). Oral tolerance and regulation of immunity to dietary antigens. In: Ogra PL, Sroben W, Mestecky J, McGhee JR, Lamm ME \& Bienenstock JE (Editors), Handbook of Mucosal Immunology. Academic Press, San Diego, 185201.

4. Brandtzaeg P (1996). History of oral tolerance and mucosal immunology. Annals of the New York Academy of Sciences, 778: $1-26$.

5. Hanson D, Vaz NM, Rawlings LA \& Lynch JM (1979). Inhibition of specific immune responses by feeding protein antigens. II. Effects of prior passive and active immunization. Journal of Immunology, 122: 2261-2266.

6. Peng H-J, Turner MW \& Strobel S (1989). The kinetics of oral hyposensitization to a protein antigen are determined by immune status and the timing, dose and frequency of antigen administration. Immunology, 67: 425-430.

7. Holt PG (1994). A potential vaccine strategy for asthma and allied atopic diseases during early childhood. Lancet, 344: 456458.

8. Staines NA \& Harper N (1995). Oral toler- ance in the control of experimental models of autoimmune disease. Journal of Rheumatology, 54: 145-154.

9. Weiner HL, Friedman A, Miller A, Khoury SJ, al Sabbagh A, Santos L, Sayegh M, Nussenblatt RB, Trentham DE \& Hafler DA (1994). Oral tolerance: Immunologic mechanisms and treatment of animal and human organ-specific autoimmune diseases by oral administration of autoantigens. Annual Review of Immunology, 12: 809-837.

10. Faria AMC, Garcia G, Rios MJC, Michalaros CL \& Vaz NM (1993). Decrease in susceptibility to oral tolerance induction and occurrence of oral immunization to ovalbumin in 20-38 week old mice. Immunology, 78: 147-151.

11. Vaz NM, Rios MJC, Lopes LM, Gontijo CM, Castanheira EB, Jacquemart F \& Andrade LAB (1987). Genetics of susceptibility to oral tolerance to ovalbumin. Brazilian Journal of Medical and Biological Research, 20: 785-790.

12. Challacombe SJ \& Tomasi TB (1980). Systemic tolerance and secretory immunity after oral immunization. Journal of Experimental Medicine, 152: 1459-1465.

13. Challacombe SJ (1983). Salivary antibodies and systemic tolerance in mice after oral immunization with bacterial antigens. Annals of the New York Academy of Sciences, 409: 177-193.

14. Stok W, van der Heidjen PJ \& Bianchi AT (1994). Conversion of orally induced sup- pression of the mucosal immune response to ovalbumin into stimulation by conjugating ovalbumin to cholera toxin or its B subunit. Vaccine, 12: 521-526.

15. Koster FT \& Pierce NF (1983). Parenteral immunization causes antigen-specific cellmediated suppression of an intestinal $\lg \mathrm{A}$ response. Journal of Immunology, 131 115-118.

16. Lafont $\mathrm{S}$, André $\mathrm{C}$, André $\mathrm{F}$, Gillon $\mathrm{J}$ \& Fargier MC (1982). Abrogation by subsequent feeding of antibody response, including $\mathrm{lg} \mathrm{E}$, in parenterally immunized mice. Journal of Experimental Medicine, 155: 1573-1578.

17. Lamont AG, Bruce MG, Watret KC \& Ferguson A (1988). Suppression of an established DTH response to ovalbumin in mice by feeding antigen after immunization. Immunology, 64: 135-139.

18. Cara DC, Conde AA \& Vaz NM (1997). Immunological induction of flavor aversion in mice. II. Passive/adoptive transfer and pharmacologic inhibition. Scandinavian Journal of Immunology, 45: 16-20.

19. Liu LM \& MacPherson GG (1993). Antigen acquisiton by dendritic cells: Intestinal dendritic cells acquire antigens administered orally and can prime naive $T$ cells in vivo. Journal of Experimental Medicine, 177: 1299-1307.

20. Flanagan M, Jain S \& Michael J (1996). Breaking of oral tolerance by an encapsulated antigen. Annals of the New York Academy of Sciences, 778: 373-375. 